\title{
CT Study of Relationship of Optic Nerve to Posterior Paranasal Sinuses
}

\author{
Anston Braggs ${ }^{1}$, Krishna Kiran $\mathbf{S}^{2}$ \\ ${ }^{1}$ Senior Resident, Depatment of Radiodiagnosis, ${ }^{2}$ Associate Professor, Depatment of Radiodiagnosis, Father Muller Medical \\ college, Kankanady, Mangaluru 575002, India
}

Corresponding author: Dr Krishna Kiran S, Department of Radiodiagnosis, Father Muller Medical College, India

DOI: http://dx.doi.org/10.21276/ijcmsr.2018.3.4.16

How to cite this article: Anston Braggs, Krishna Kiran S. CT study of relationship of optic nerve to posterior paranasal sinuses. International Journal of Contemporary Medicine Surgery and Radiology. 2018;3(4):D71-D73.

\section{A B S T R A C T}

Introduction: Functional endoscopic sinus surgery (FESS) is the accepted technique for treatment of sinusitis. CT of paranasal sinuses is the roadmap from which FESS is planned. One has to be aware of optic nerve course in relation to posterior paranasal sinuses to avoid injury. We wanted to determine relationship of optic nerves to posterior paranasal sinuses and its various types, their incidence according to DeLano classification.

Materials and methods: 500 paranasal sinuses were examined over a period of three years from September 2015 to September 2018. Relationship of optic nerves to posterior paranasal sinuses was categorized according to DeLano classification.

Results: Type 1 had a prevalence of $61.8 \%$, type 2 had a prevalence of $17.8 \%$, type 3 had a prevalence of $7.6 \%$, type 4 had a prevalence of $12.8 \%$.

Conclusion: Sphenoid sinus and optic nerve relation is known for its variation. DeLano classification is a useful way in looking at location of optic nerve and posterior paranasal sinuses.

Key words: Optic Nerve, Posterior Paranasal Sinuses, Delano Classification

\section{INTRODUCTION}

The term posterior paranasal sinuses includes posterior ethmoid and sphenoid sinuses.

Optic nerve develops prior to development of paranasal sinuses, hence is responsible for congenital variations along wall of paranasal sinuses. ${ }^{1}$ Close anatomical relation between orbits and posterior paranasal sinuses places the optic nerve at risk during FESS. ${ }^{2}$ Enormous variation has been recognized in anatomy of sphenoid and posterior ethmoid sinuses. DeLano et al proposed a classification for better understanding of regional anatomy. ${ }^{3}$ We wanted to determine incidence and prevalence of similar classification in patients visiting our hospital.

\section{MATERIAL AND METHODS}

The study was conducted in Father Muller Medical College Hospital, Mangaluru, Karnataka in the department of Radio-Diagnosis. A total of 500 optic nerves were evaluated retrospectively. Patients who underwent computed tomography (CT) of the paranasal sinuses (PNS) as a routine for sinusitis were selected retrospectively from Sept 2015 Sept 2018 (Duration of 3 years).

Inclusion criteria

- All patients aged between 18 and 90 years with clinical suspicion of sinusitis

\section{Exclusion criteria}

- Patients aged less than 18 years and above 90 years
- Patients with neoplastic lesions of the PNS.

- Patients with fractures/trauma to the PNS.

CT protocol: CT was done with patient in prone position with 16 slice Helical Multi Detector CT (GE Bright Speed), $1.25 \mathrm{~mm}$ thickness, coronal sections in bone window, Kv: 120 and mAs: $100-150$.

The optic nerves were classified according to Delano classification: which states

Type 1- Optic nerve is immediately adjacent to lateral and superior wall of sphenoid sinus without impression on sinus wall.

Type 2 - Optic nerve causes an impression on lateral sphenoidal sinus wall.

Type 3 - Optic nerve courses through the sphenoid sinus.

Type 4-Optic nerve courses immediately lateral to posterior ethmoid and sphenoid sinuses.

\section{STATISTICAL ANALYSIS}

Descriptive statistics like mean and percentages were used for analysis.

\section{RESULTS}

250 patients underwent CT of paranasal sinuses during study period and course of 500 optic nerves was examined in relation to posterior paranasal sinuses. Type 1 course was present in 309 optic nerves (61.8\%). Type 2 appearance was present in 89 optic nerves (17.8\%). Type 3 course was present in 38 optic nerves (7.6\%). Type 4 appearance was present in 


\begin{tabular}{|l|c|c|}
\hline & Subjects (n) & Percentage (\%) \\
\hline Male & 295 & 59 \\
\hline Female & 205 & 41 \\
\hline Total & 500 & 100 \\
\hline \multicolumn{2}{|c|}{ Table-1: Depicting sex ratio of included patients. } \\
\hline
\end{tabular}

\begin{tabular}{|l|c|c|c|c|}
\hline Type of optic nerve & Right & Left & Total & Percentage \\
\hline 1 & 88 & 84 & 172 & $58.31 \%$ \\
\hline 2 & 24 & 26 & 50 & $16.95 \%$ \\
\hline 3 & 13 & 14 & 27 & $9.15 \%$ \\
\hline 4 & 22 & 24 & 46 & $15.59 \%$ \\
\hline Total & 147 & 148 & 295 & $100 \%$ \\
\hline \multicolumn{5}{|c|}{ Table-2: Shows incidence of different types of optic canal } \\
\hline
\end{tabular}

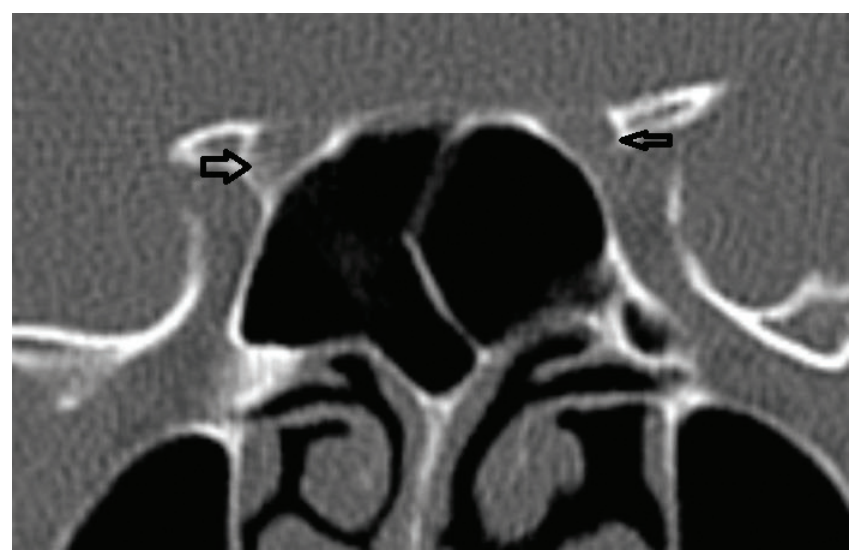

Figure-1: Coronal sections of paranasal sinuses showing type 1 optic nerve canal configuration. Arrows show location of optic nerves bilaterally. Here canals are lateral to sphenoid wall without indentation.

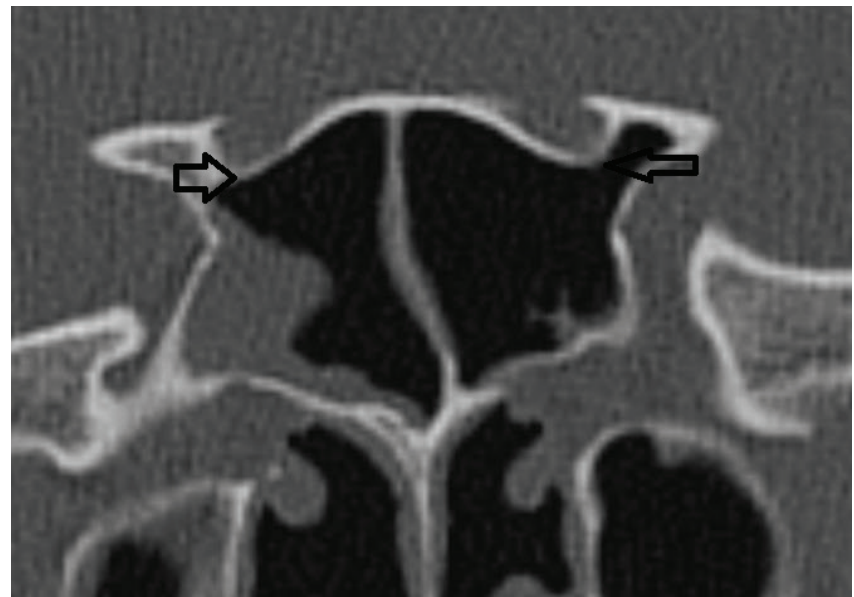

Figure-2: Coronal sections of paranasal sinuses reveal type 2 optic canal configuration. Arrows reveal optic nerves causing impression on sphenoid sinus wall. There is also mucosal thickening present in right sphenoid sinus.

64 optic nerves (12.8\%). Of 250 patients, 148 (59\%) were males and 102 (41\%) were females.

There was not much difference between right and left sides. Type 1 optic nerve morphology was present in 159 right and 150 left optic nerves. Type 2 morphology was present in 46 right and 43 left optic nerves. Type 3 morphology was present in 18 right and 20 left optic nerves. Type 4 morphology was

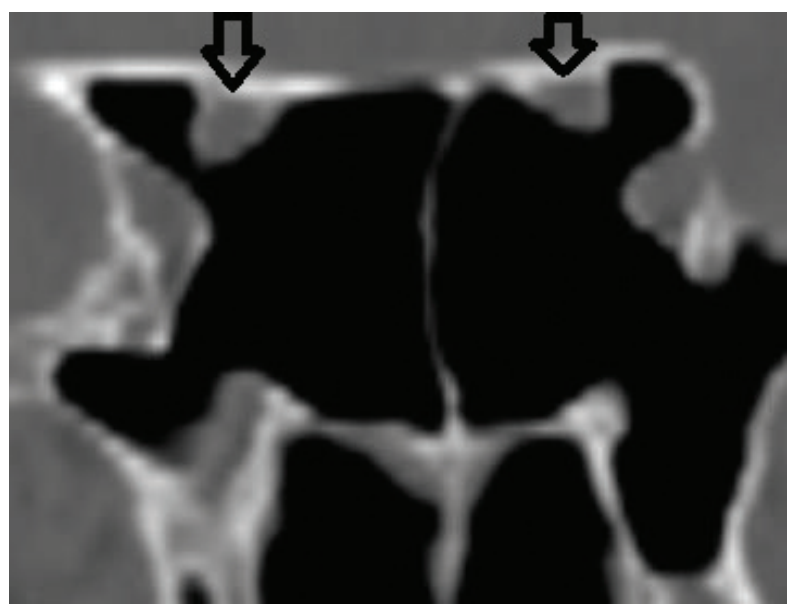

Figure-3: Coronal sections of paranasal sinuses revealing type 3 optic nerve canal configuration. Arrows reveal dehiscent optic nerve canals coursing within sphenoid sinus.

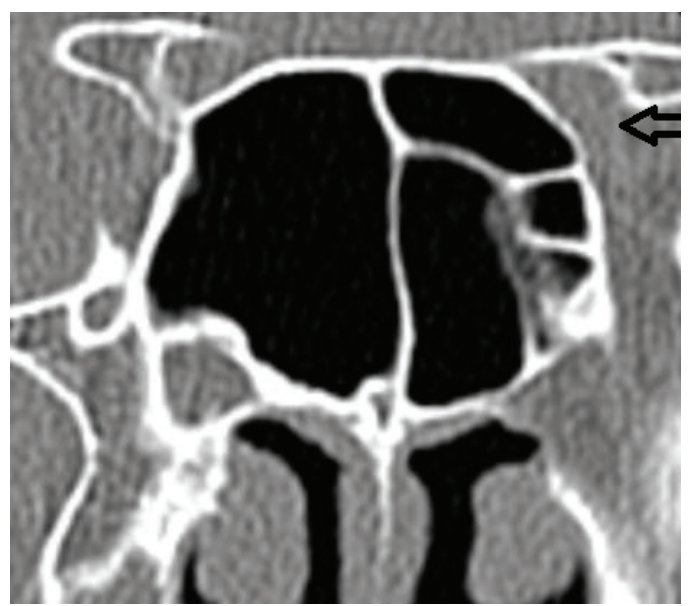

Figure-4: Type 4 Optic nerve canal. Arrows reveal left optic nerve canal located adjacent to posterior ethmoid sinuses.

present in 32 right and left optic nerves.

\section{DISCUSSION}

Sphenoid sinus is an aerated mucosa lined cavity occupying central location in skull bone. It is present at birth, pneumatization continues into adulthood. Pneumatization pattern is variable and can extend to surround adjacent structures. Varied relation of optic nerve to paranasal sinuses is attributed to inconsistent pneumatization pattern of sphenoid sinus. ${ }^{4}$

DeLano et al were amongst the first to study relation of optic nerves to posterior paranasal sinuses and to devise a classification system. Of 300 optic nerves studied by them $228(76 \%)$ had type 1 configuration, $44(15 \%)$ had type 2 configuration, 19 (6\%) had type 3 configuration and 9 (3\%) had type 4 configuration. They also looked for pneumatization of anterior clinoid process which was present in 13 optic nerve canals and also dehiscence of optic nerve which was present in 10 among them.

Similar study was conducted in Turkish population in Sapei et al. $^{5}$ They reviewed CT scans in 100 patients and found type 1 configuration in 64\%, type 2 configuration in $22 \%$, type 3 and type 4 configuration in $7 \%$ each.

Batra et al modified DeLano classification further. ${ }^{6}$ They 
did high resolution CT scans of 64 frozen human cadavers on a Siemens Volume Zoom and did a software enabled CT analysis of optic nerve position and paranasal sinus pneumatization pattern. They categorized pneumatization around optic nerve into 5 types. Type 1 - there is no adjacent pneumatization. Type 2- pneumatization adjacent to optic nerve. Type 3- adjacent pneumatization with indentation. Type 4- pneumatization with involvement of less than 50\% optic nerve circumference. Type 5- pneumatization with involvement of more than $50 \%$ optic nerve circumference.

Itagi et al also followed a slightly modified version of DeLano classification. $^{7}$ Their study found Type 1 at $60 \%$, type 2 at $15 \%$, type 3 at $14 \%$ and type 4 at $11 \%$.

In comparison with DeLano et al, commonest type in our study was also type 1 . Overwhelming percentage in DeLano study was type 1 at $76 \%$, in our study type 1 is at $61.8 \%$. We also had higher (12.8\%) incidence of type 4 compared to $3 \%$ in study by DeLano. Itagi et al also had higher percentage of type 4 at $11 \%$ similar to our study. This could be due to similar population covered in both studies.

We did not include incidence of pneumatization of anterior clinoid process that was included in by DeLano and few others because aim of our study was to study relationship of optic nerves to posterior paranasal sinuses.

\section{CONCLUSION}

Sphenoid sinus and optic nerve relation is known for its variation. Before endoscopic sinus surgery, one needs to know this anatomy using CT of paranasal sinuses. DeLano classification is a helpful way in looking at location of optic nerve and posterior paranasal sinuses.

\section{REFERENCES}

1. Reddy UD, Dev B. Pictorial essay: Anatomical variations of paranasal sinuses on multidetector computed tomography-How does it help FESS surgeons?. Indian J Radiol Imaging. 2012;22(4):317-24.

2. Kim JY, Kim HJ, Kim CH, Lee JG, Yoon JH. Optic nerve injury secondary to endoscopic sinus surgery: an analysis of three cases. Yonsei Med J. 2005;46(2):300-4.

3. DeLano MC, Fun FY, Zinreich SJ. Relationship of the optic nerve to the posterior paranasal sinuses: a CT anatomic study. AJNR American journal of neuroradiology. 1996;17(4):669-75.

4. A.J. Fasunla, S.A. Ameye, O.S. Adebola, G. Ogbole, A.O. Adeleye, A.J. Adekanmi. Anatomical Variations of the Sphenoid Sinus and Nearby Neurovascular Structures Seen on Computed Tomography of Black Africans. East and central African journal of surgery 2012, 17(1): 57-64.

5. Sapci T, Derin E, Almac S, Cumali R, Saydam B, Karavus M. The relationship between the sphenoid and the posterior ethmoid sinuses and the optic nerves in Turkish patients. Rhinology. 2004;42(1):30-34.

6. Batra PS, Citardi MJ, Gallivan RP. Software-enabled $\mathrm{CT}$ analysis of optic nerve position and paranasal sinus pneumatization patterns. Otolaryngol Head Neck Surg 2004; 131(2):940-945.

7. Itagi RM, Adiga CP, Kalenahalli K, Goolahally L, Gyanchandani M. Optic Nerve Canal Relation to
Posterior Paranasal Sinuses in Indian Ethnics: Review and Objective Classification. J Clin Diagn Res. 2017;11(4):TC01-TC03.

\section{Source of Support: Nil; Conflict of Interest: None}

Submitted: 12-10-2018; Accepted: 14-11-2018; Published online: 25-11-2018 